\title{
Production of a dibrominated aromatic secondary metabolite by a planctomycete implies complex interaction with a macroalgal host
}

\author{
Fabian Panter ${ }^{[a, b]}$, Ronald Garcia ${ }^{[a, b]}$, Angela Thewes ${ }^{[a, b]}$, Nestor Zaburannyi ${ }^{[a, b]}$, Boyke Bunk ${ }^{[b, c]}$, Jörg \\ Overmann ${ }^{[b, c]}$, Mary V. Gutierrez ${ }^{[d]}$, Daniel Krug ${ }^{[a, b]}$ and Rolf Müller* [a,b]
}

\begin{abstract}
[a] Department of Microbial Natural Products, Helmholtz-Institute for Pharmaceutical Research Saarland (HIPS), Helmholtz Centre for Infection Research (HZI) and Department of Pharmacy, Saarland University, Campus E8 1, 66123 Saarbrücken, Germany

[b] German Centre for Infection Research (DZIF), Partner Site Hannover-Braunschweig, Germany

[c] Leibniz Institute DSMZ-German Collection of Microorganisms and Cell Cultures, Inhoffenstr. 7B, 3814 Braunschweig, Germany

[d] Biology department, Far Eastern University Nicanor Reyes St. Sampaloc, Manila, 1008 Metro Manila, Philippines
\end{abstract}

\section{Supporting Information}




\section{Table of contents}

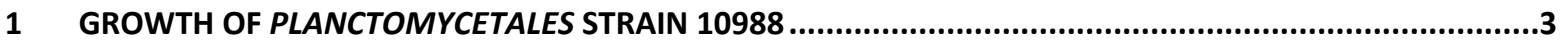

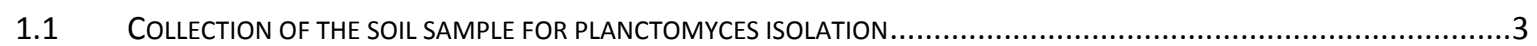

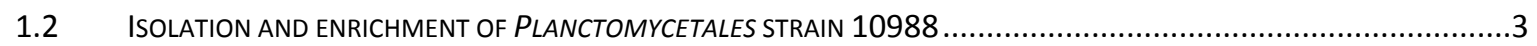

1.3 MEDIA RECIPES USED IN PLANCTOMYCETES CULTIVATION .....................................................................

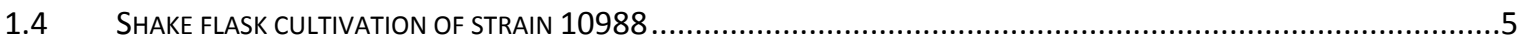

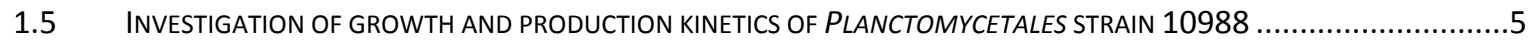

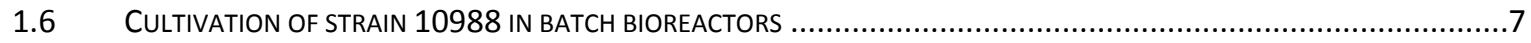

1.6.1 Fermentation optimization in $1 \mathrm{~L}$ bioreactors.................................................................

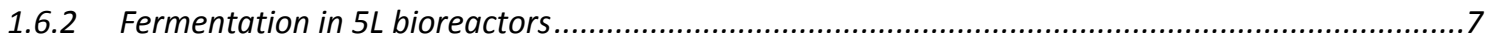

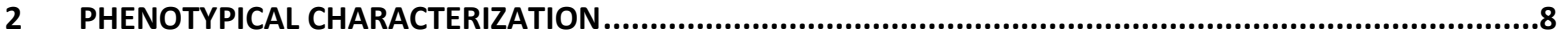

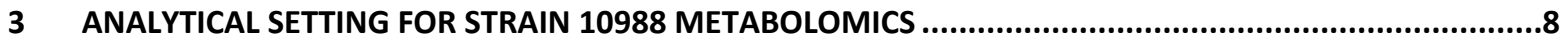

EXTRACTION OF ANALYTICAL SCALE CULTURES FOR UPLC-MS ANALYSIS..................................................

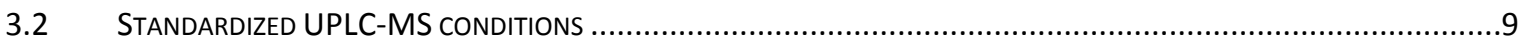

4 ISOLATION, PURIFICATION AND CHARACTERIZATION OF 3,5 DIBROMO P-ANISIC ACID ......................10

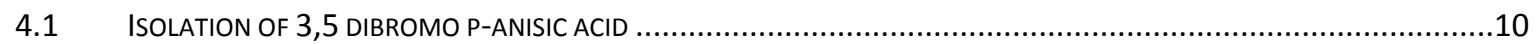

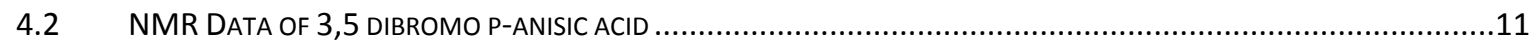

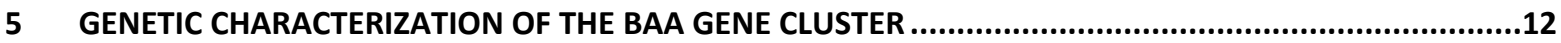

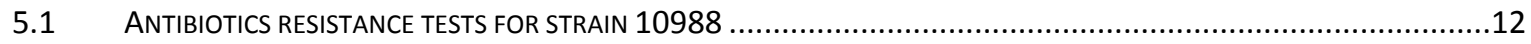

5.2 GENOME SEQUENCING AND GENE CLUSTER ANNOTATION AND ACCESSION NUMBER .....................................12

5.3 PhyR 2 RESUltS FOR MOdelLING THE PLANCTOMYCETAL ENZYMES BAAA AND BAAB....................................13

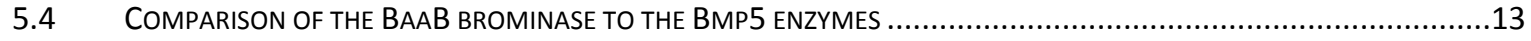

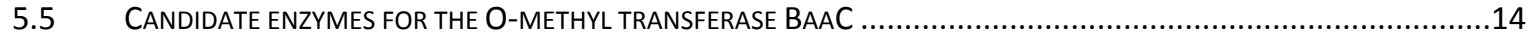

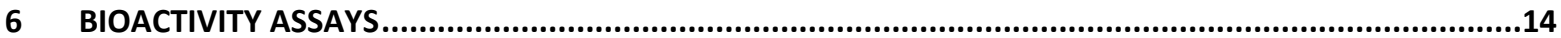

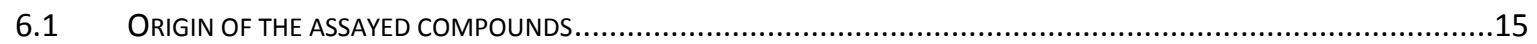

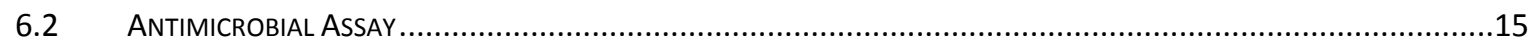

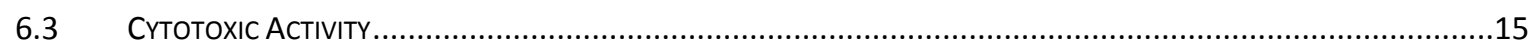

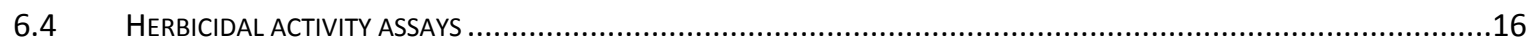

$7 \quad$ NMR SPECTRA OF NATURAL 3,5 DIBROMO P-ANISIC ACID ....................................................17

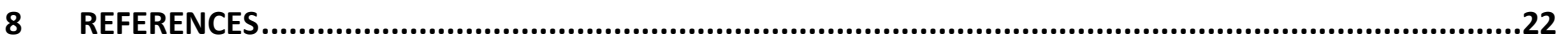




\section{Growth of Planctomycetales strain 10988}

\subsection{Collection of the soil sample for planctomyces isolation}

The sample was collected in Batangas, Philippines in an area within the Verde Island Passage (VIP) where it is recognized by many as a diverse site for marine life. The sand sample was from a reef area with diverse algae (e.g. Chlorophyta, Phaeophyta, etc), corals and other marine life. The whole stretch of Mabini peninsula and Bauan Balayan Bay of the VIP is a world known diving site. Exact coordinates of the sample

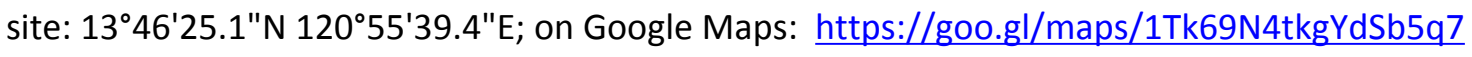

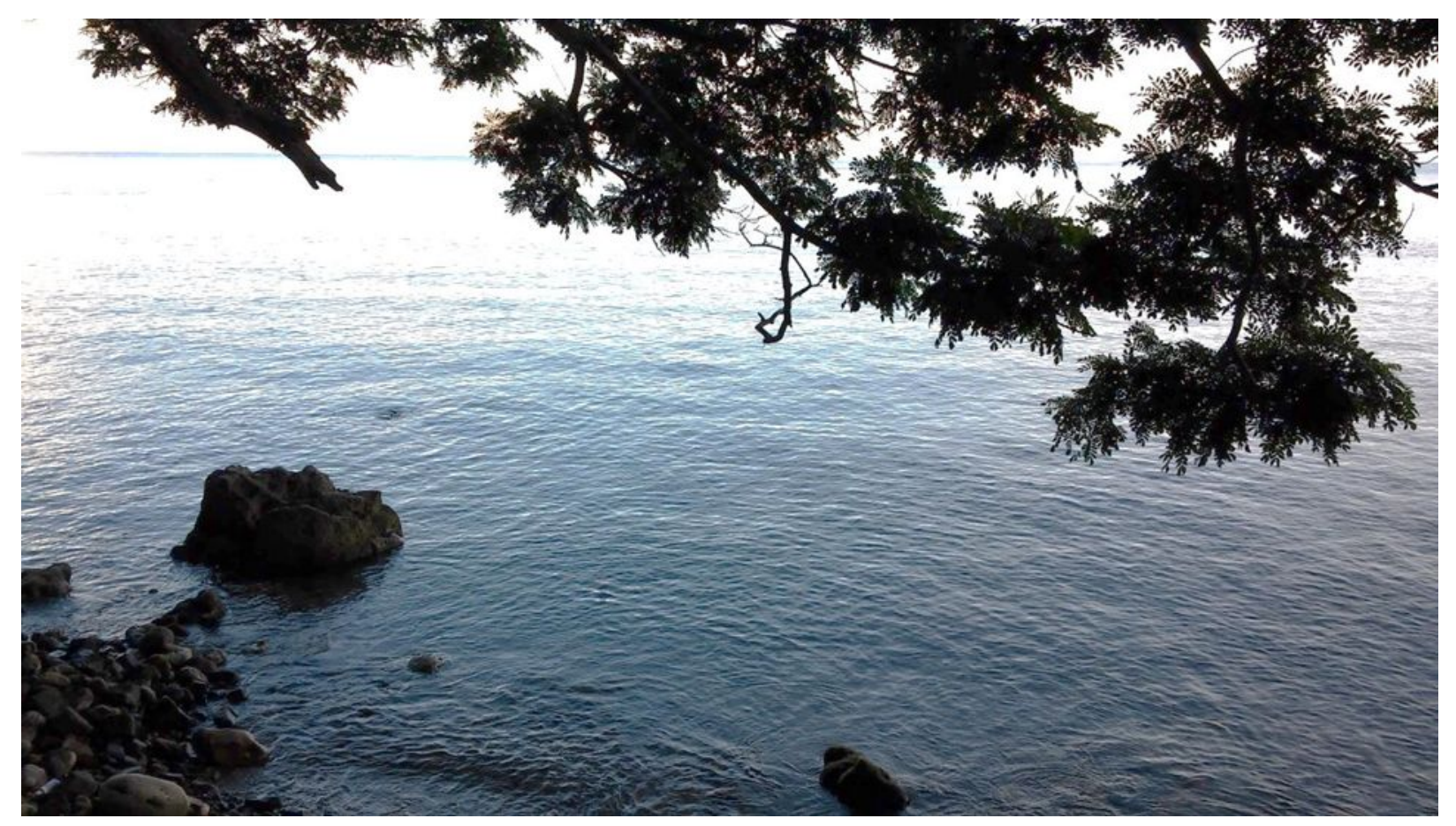

Figure S 1. Picture of the sampling site in Batangas, Philippines 


\subsection{Isolation and enrichment of Planctomycetales strain 10988}

Planctomycetales strain 10988 was isolated from a sand sample collected in Batangas, Philippines using an isolation set-up for marine myxobacteria. The sand sample was placed on an agar plate [Ferric citrate $0.01 \mathrm{~g} / \mathrm{L}, \mathrm{MgSO}_{4} \cdot 7 \mathrm{H}_{2} \mathrm{O} 8.0 \mathrm{~g} / \mathrm{L}, \mathrm{CaCl}_{2} \cdot 2 \mathrm{H}_{2} \mathrm{O} 1.0 \mathrm{~g} / \mathrm{L}, \mathrm{NaCl} 3 \mathrm{~g} / \mathrm{L}, \mathrm{KCl} 0.5 \mathrm{~g} / \mathrm{L}, \mathrm{NaHCO}_{3} 0.16 \mathrm{~g} / \mathrm{L}$, $\mathrm{H}_{3} \mathrm{BO}_{3} 0.02 \mathrm{~g} / \mathrm{L}, \mathrm{KBr} 0.08 \mathrm{~g} / \mathrm{L}, \mathrm{SrCl}_{2} \cdot 6 \mathrm{H}_{2} \mathrm{O} 0.03 \mathrm{~g} / \mathrm{L}$, di-Na-ß-glycerophosphate $0.01 \mathrm{~g} / \mathrm{L}$, trace element solution $1.0 \mathrm{~mL} / \mathrm{L}, \mathrm{BD}$ Bacto Agar $15 \mathrm{~g} / \mathrm{L}$, HEPES $1.19 \mathrm{~g} / \mathrm{L}$, dissolved in DI water, pH adjusted to 7.2 with $\mathrm{NaOH}$ before autoclaving] and baited with 4 strips $(1 \times 1 \mathrm{~cm})$ of sterile filter paper. The strain was detected by its ability to form a thin and transparent swarming colony radiating from the inoculum on the agar plate. After repeated cutting of the swarm edge and transferring it to the agar same medium supplemented with autoclaved Baker's yeast $(5 \mathrm{~g} / \mathrm{L})$, the strain was isolated and purified. The strain can be stored as a $50 \%$ glycerol stock remaining viable at $-80^{\circ} \mathrm{C}$.

\subsection{Media recipes used in planctomycetes cultivation}

Planctomycetales strain 10988 was grown in solid and liquid culture on PYMA medium to propagate the strain. For creation of solid media $16 \mathrm{~g} / \mathrm{L}$ agarose (Sigma Aldrich) are added to the liquid medium before autoclaving.

Table 1. Medium recipe of PYMA medium used to propagate 10988

\begin{tabular}{|c|c|c|}
\hline \multicolumn{2}{|c|}{ PYMA Medium } & Supplier \\
\hline Ingredient & Concentration & STI \\
\hline Sea Salts & $36 \mathrm{~g} / \mathrm{L}$ & Merck \\
\hline trizma base & $10 \mathrm{mM}$ & BD \\
\hline Peptone from soy meal & $0.15 \mathrm{~g} / \mathrm{L}$ & Sigma Aldrich \\
\hline yeast extracs & $0.15 \mathrm{~g} / \mathrm{L}$ & VWR \\
\hline $\mathrm{D}(+)$ maltose monohydrate & $1 \mathrm{~g} / \mathrm{L}$ & $0.25 \mathrm{~g} / \mathrm{L}$ \\
\hline $\mathrm{NH}_{4} \mathrm{SO}_{4}$ & $\mathrm{pH}$ is adjusted to 7.5 with $\mathrm{HCl}$ before autoclaving \\
\hline
\end{tabular}

For fermentation, the medium was optimized to produce a maximal amount of 3,5 dibromo $p$-anisic acid. As yield evaluations point to ECX medium as the best tested medium in terms of 3,5 dibromo $p$-anisic acid production fermentative production was performed in ECX medium. 
Table 2. Medium recipe for ECX medium used for fermentative production of 3,5 dibromo p-anisic acid

\begin{tabular}{|c|c|c|}
\hline \multicolumn{2}{|c|}{ PYMA Medium } & Supplier \\
\hline Ingredient & $32 \mathrm{~g} / \mathrm{L}$ & STI \\
\hline Sea Salts & $4 \mathrm{~g} / \mathrm{L}$ & Sigma Aldrich \\
\hline $\mathrm{NaBr}$ & $10 \mathrm{mM}$ & Merck \\
\hline trizma base & $2 \mathrm{~g} / \mathrm{L}$ & Merck \\
\hline Peptone from soy meal & $1 \mathrm{~g} / \mathrm{L}$ & Roth \\
\hline Meat extract & $1 \mathrm{~g} / \mathrm{L}$ & ACROS \\
\hline Lactose & $1 \mathrm{~g} / \mathrm{L}$ TCl biochemicals \\
\hline Sucrose & $1 \mathrm{~g} / \mathrm{L}$ & BD \\
\hline Xylose & $1 \mathrm{~g} / \mathrm{L}$ & Sigma Aldrich \\
\hline Raffinose & $1 \mathrm{~g} / \mathrm{L}$ & Access Bio \\
\hline Casitone & $4 \mathrm{~g} / \mathrm{L}$ & $2 \mathrm{~g} / \mathrm{L}$ \\
\hline $\mathrm{D}(+)$ maltose monohydrate & & \\
\hline Cellulose fiber (Grade BER 40) & pH is adjusted to 7.5 with $\mathrm{HCl}$ before autoclaving, add $200 \mu \mathrm{g} / \mathrm{L}$ Vitamin B12 solution after autoclaving \\
\hline
\end{tabular}

\subsection{Shake flask cultivation of strain 10988}

Cultures for UHPLC/HRMS analysis were grown in $300 \mathrm{ml}$ shake flasks containing $50 \mathrm{ml}$ of ECX or PYMA medium for strain 10988 inoculated with $1 \mathrm{ml}$ of pre-culture. After inoculation the medium was supplemented with $2 \%(\mathrm{v} / \mathrm{v})$ of sterile XAD-16 adsorber resin (Sigma Aldrich) suspension in water if the culture was to be extracted. For propagation of the cells in liquid medium, the cultures were grown without XAD-16 adsorber resin. Strain 10988 is cultivated at $28^{\circ} \mathrm{C}$ for 21 days on an orbitron rotatory shaker at 160 rpm.

\section{Investigation of growth and production kinetics of Planctomycetales strain 10988}

In order to elucidate at what growth stage 10988 produces our target compound we chose to investigate secondary metabolite growth kinetics and production kinetics of 3,5 dibromo p-anisic acid at the same time. 18 separate sets of cultures were grown according to the shake flask growth protocol, which are all inoculated by the same pre culture. Every two days, two shake flasks were harvested and extracted according to the analytical scale extraction protocol. Before centrifuging the culture, $1 \mathrm{ml}$ of culture broth was taken out after the cellulose in the medium has settled in order to measure the cultures OD 600 value that is proportional to cell density with an Eppendorf BioPhotometer plus. If the OD 600 
approached 0.5 or higher, the OD is measured from serial dilutions to ensure accuracy of the value. Purity of the strain was checked under a light microscope to ensure measuring OD 600 values from contamination free cultures. The rest of the culture was extracted according to the analytical scale extraction protocol for UHPLC-MS analyses and analyzed via UHPLC-MS according to standard conditions. 3,5 dibromo p-anisic acid was quantified by peak area of the most intense isotopic ion of $310.873 \mathrm{Da}[\mathrm{M}+\mathrm{H}]^{+}$.

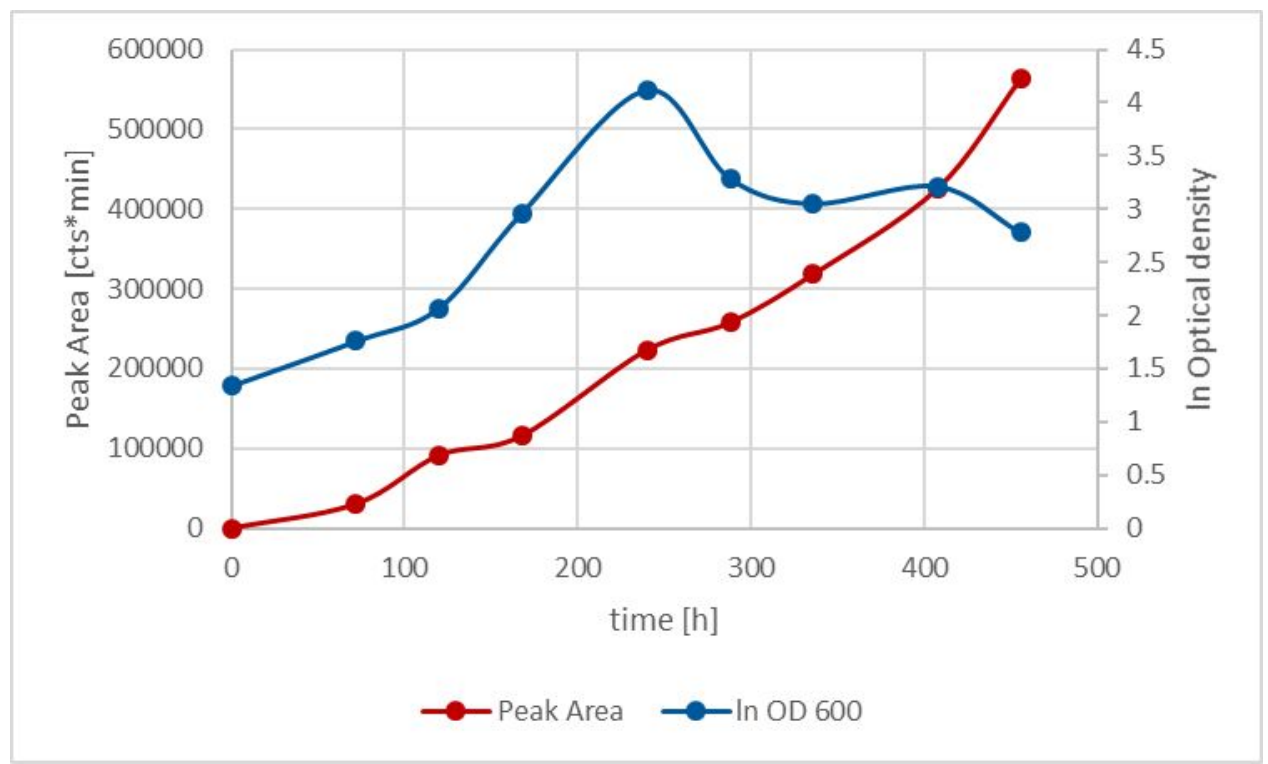

Figure S 2. Growth and production kinetics of 3,5 dibromo p-anisic acid in 10988

It should be noted that after approximately 11 days the cell density peaked. Afterwards, dying cells start forming cell clumps and debris, which made the optical density fall faster than one would expect if dead cells would have remained in suspension.

Table 3. Optical density of strain 10988 cultures and peak area of 3,5 dibromo p-anisic acid in the culture extract

\begin{tabular}{c|cccc}
$\mathrm{t}[\mathrm{h}]$ & $\begin{array}{c}\text { OD 600 } \\
\text { Shake flask 1 }\end{array}$ & $\begin{array}{c}\text { OD 600 } \\
\text { Shake flask 2 }\end{array}$ & $\begin{array}{c}\text { Peak area } \\
\text { Shake flask 1 }\end{array}$ & $\begin{array}{c}\text { Peak area } \\
\text { Shake flask 2 }\end{array}$ \\
\hline 0 & 2,61 & 1,21 & 0 & 0 \\
72 & 2,71 & 3,1 & 25503 & 35219 \\
120 & 4,44 & 3,48 & 77993 & 104681 \\
168 & 8,3 & 11,0 & 96643 & 135500 \\
240 & 37,1 & 24,0 & 270906 & 176006 \\
288 & 13,2 & 13,6 & 212728 & 302992 \\
336 & 11,9 & 9,2 & 290473 & 345969 \\
408 & 17,2 & 7,6 & 453838 & 398107 \\
456 & 7,2 & 8,9 & 623366 & 503019
\end{tabular}




\subsection{Cultivation of strain 10988 in batch bioreactors}

\subsubsection{Fermentation optimization in $1 \mathrm{~L}$ bioreactors}

In order to optimize fermentation for efficient production of 3,5 dibromo $p$-anisic acid we tested the parameters in an 1L Infors HT fermenter (Art. No. 26133) equipped with two 6 blade plate stirrers with a diameter of $5 \mathrm{~cm}$. The fermenter was gassed with synthetic air (1.5 bar), $\mathrm{pO}_{2}$ and $\mathrm{pH}$ are logged with respective electrodes during fermentation. The fermenter was connected to 4 different Schott bottles containing $1 \mathrm{M} \mathrm{H}_{2} \mathrm{SO}_{4}, 1 \mathrm{M} \mathrm{NaOH}$ for $\mathrm{pH}$ control, an 1/10 dilution of Antifoam Y-30 Emulsion (Sigma) in DI water and an empty Schott bottle for inoculation. The bioreactor was filled with $1 \mathrm{~L}$ of ECX medium supplemented with $5 \mathrm{ml}$ of undiluted Antifoam Y-30 Emulsion. After autoclaving at $121^{\circ} \mathrm{C}$ for $30 \mathrm{~min}$, electrodes were connected to the fermenter and the default values for the fermentation are put in. $\mathrm{pH}$ is set to 7.2 , stirring speed to $150 \mathrm{rpm}$ and fermentation temperature is set to $28^{\circ} \mathrm{C}$. Temperature was taken from the fermentation broth via a thermocouple that is planted in a blind tube in the fermentation broth. Inoculation was done with an autoclaved glass syringe and a steel needle that can be flame sterilized before inoculation. The fermenter was inoculated with $50 \mathrm{ml}$ of a well grown planctomycetal pre culture in a $300 \mathrm{ml}$ shake flask filled with $50 \mathrm{ml}$ ECX medium. The OD600 value should exceed 2 and the culture should be intensely rose colored. This inoculation broth was injected into the empty schott bottle and introduced into the fermenter via excess air pressure. After 5 to 7 days depending on the growth speed, $20 \mathrm{ml}$ of a sterile XAD-16 adsorber resin solution (Sigma Aldrich, 50/50 vol \%) were added to the fermenter to remove excess 3,5 dibromo $\mathrm{p}$-anisic acid from the broth and prevent feedback inhibition. Fermentation was done after 15 to 21 days depending on the lag phase. Fermentation broth was harvested by centrifugation at $16000 \times \mathrm{g}$ for 10 min with a Beckman Coulter Avanti J-26XP Centrifuge and the supernatant is discarded.

\subsubsection{Fermentation in 5L bioreactors}

Fermentation was performed in a 5L Infors HT bioreactor (Art. No. 26128) equipped with two 6 blade plate stirrers with a diameter of $5 \mathrm{~cm}$. Fermentation was performed largely analogous to the $1 \mathrm{~L}$ bioreactor fermentation experiments. Inoculation volume was changed to $200 \mathrm{ml}$ pre culture broth to ensure good colonization of the fermenter and stirring speed is elevated to $200 \mathrm{rpm}$. As for the $1 \mathrm{~L}$ bioreactor experiments, $200 \mathrm{ml}$ sterile XAD-16 adsorber resin solution (Sigma Aldrich, 50/50 vol \%) was added to the fermenter broth after 7 days of fermentation. Fermentation end point was determined after 16 to 20 days depending on the batch and workup is performed analogous to the $1 \mathrm{~L}$ fermentation. 


\section{Phenotypical characterization}

The Planctomycetales stain 10988 occurs in three distinct phenotypes on agar plates. The strain occured as a fast swarming white or rose color phenotype and a slower swarming green phenotype. In liquid medium, the strain showed uniquely the rose color phenotype

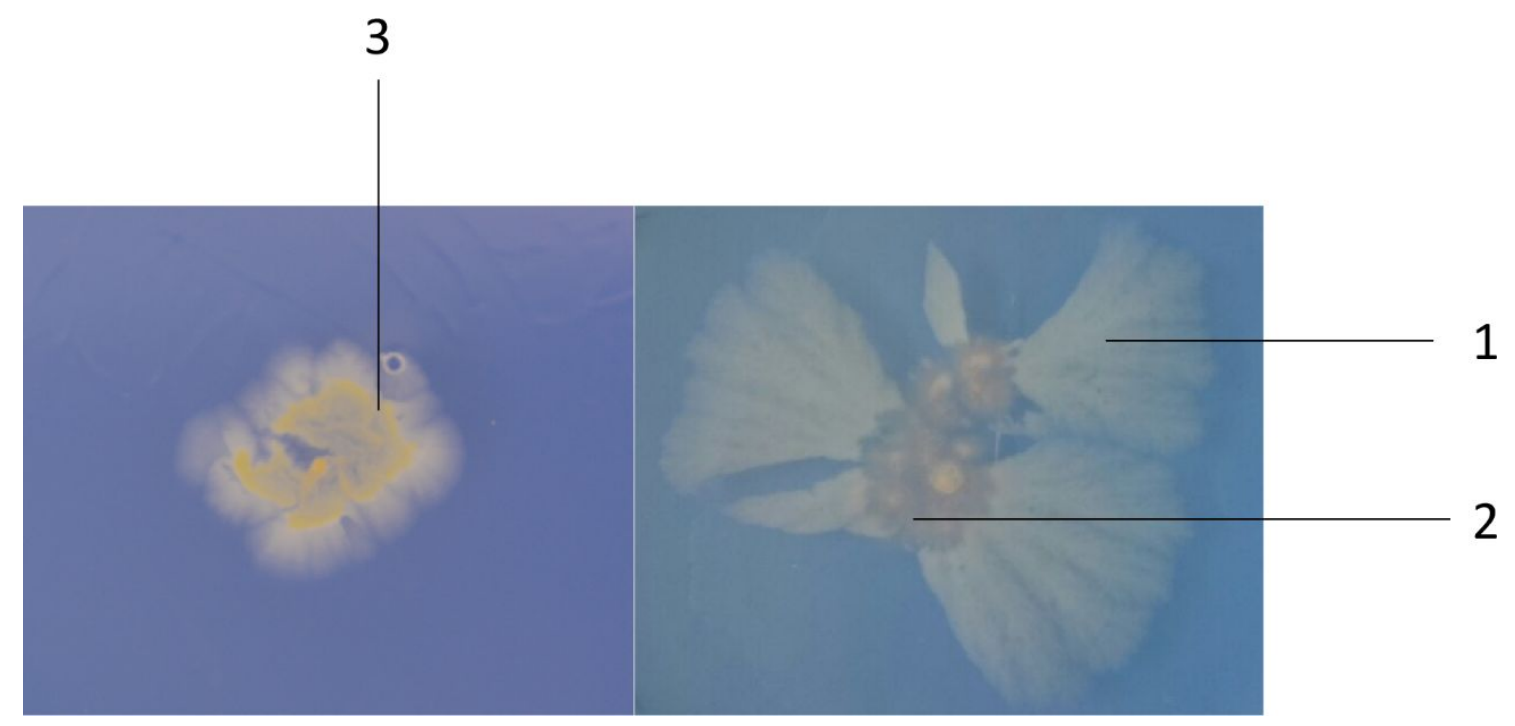

Figure S 3. Images of the three distinct phenotypes of 10988 in PYMA agar depicting the white (1), rose (2) and green phenotype (3)

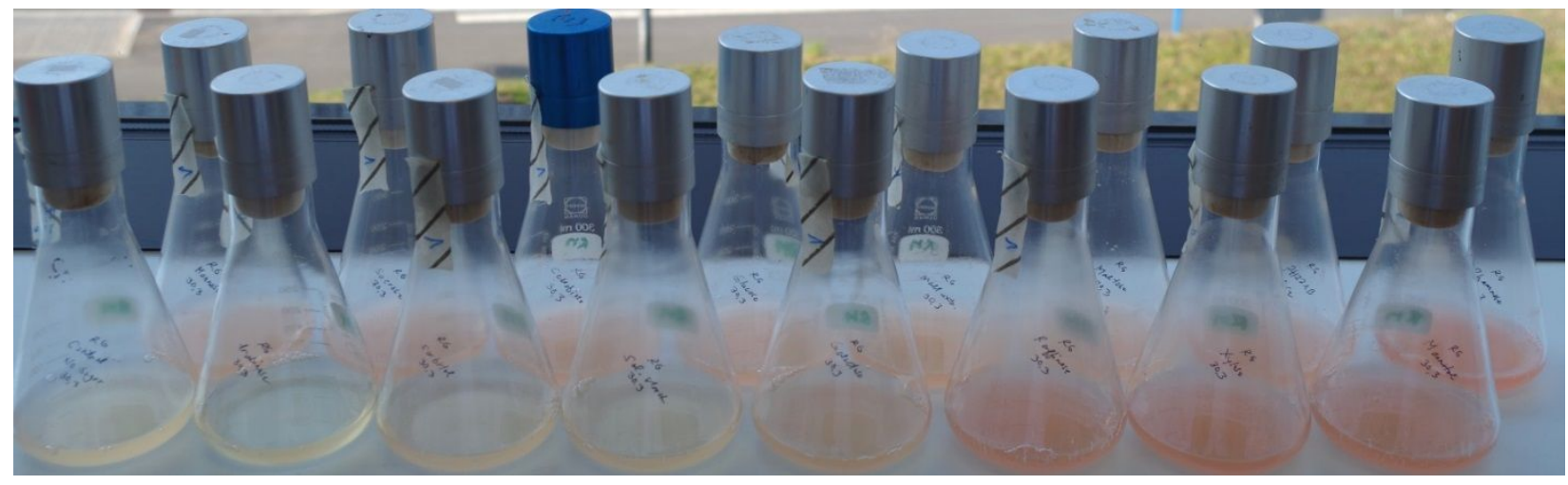

Figure S 4. Image of the rose color phenotype observed in liquid suspension culture supplemented with different sugar sources. 


\section{Analytical setting for strain 10988 metabolomics}

\subsection{Extraction of analytical scale cultures for UPLC-MS analysis}

The frozen cell pellet was transferred into a $100 \mathrm{ml}$ Erlenmeyer flask and a magnetic stirrer is added. $50 \mathrm{ml}$ of methanol (fluka, technical grade) were added onto the pellet and the mixture is stirred for 60 min. on a stirring plate. The extract was left to settle in order to sediment cell debris and XAD resin for a second extraction step. The supernatant was filtered through a 125 micron folded filter keeping cell pellet and XAD-16 resin in the Erlenmeyer flask for a second extraction step. The residual pellet and XAD-16 resin was extracted again with $30 \mathrm{ml}$ of acetone (fluka, technical grade) for $60 \mathrm{~min}$ on a stirring plate and filtered through the same folded filter. The combined extracts were transferred into a $100 \mathrm{ml}$ round bottom flask. The solvent was evaporated on a rotary evaporator at $260 \mathrm{mbar}$ and $40{ }^{\circ} \mathrm{C}$ water bath temperature. The residual water was evaporated at 20 mbar until the residue in the flask is completely dry. The residue was taken up in $500 \mu \mathrm{l}$ of methanol (Chromasolv HPLC grade, Sigma Aldrich) and transferred into a $1.5 \mathrm{ml}$ Eppendorf tube. This tube is centrifuged with a table centrifuge at $21500 \mathrm{rcf}$ for 5 minutes to remove residual insolubilities such as salts, cell debris and XAD fragments.

\section{Standardized UPLC-MS conditions}

All measurements were performed on a Thermo Scientific (Bremen, Germany) Ultimate 3000 RSLC system using a Waters (Eschborn, Germany) BEH C18 column (50 x $2.1 \mathrm{~mm}, 1.7 \mu \mathrm{m})$ equipped with a Waters VanGuard BEH C18 $1.7 \mu \mathrm{m}$ guard column. Separation of $1 \mu \mathrm{l}$ sample volume was achieved by a linear gradient from (A) $\mathrm{H}_{2} \mathrm{O}+0.1 \% \mathrm{FA}$ to (B) $\mathrm{ACN}+0.1 \% \mathrm{FA}$ at a flow rate of $600 \mu \mathrm{L} / \mathrm{min}$ and a column oven temperature of $45^{\circ} \mathrm{C}$. Gradient conditions were as follows: $0-0.5 \mathrm{~min}, 5 \% \mathrm{~B} ; 0.5-18.5 \mathrm{~min}, 5-95 \%$ B; 18.5 - $20.5 \mathrm{~min}, 95 \%$ B; 20.5 - $21 \mathrm{~min}, 95$ - 5\% B; 21-22.5 min, 5\% B. UV spectra were recorded by a DAD in the range from 200 to $600 \mathrm{~nm}$. The LC flow was split to $75 \mu \mathrm{L} / \mathrm{min}$ before entering the Bruker Daltonics maXis 4G hrToF mass spectrometer (Bremen, Germany) using the Apollo II ESI source. Mass spectra were acquired in centroid mode ranging from $150-2500 \mathrm{~m} / \mathrm{z}$ at a $2 \mathrm{~Hz}$ full scan rate. Mass spectrometry source parameters are set to $500 \mathrm{~V}$ as end plate offset; $4000 \mathrm{~V}$ as capillary voltage; nebulizer gas pressure $14.5 \mathrm{psi}$; dry gas flow of $5 \mathrm{l} / \mathrm{min}$ and a dry temperature of $200^{\circ} \mathrm{C}$. Ion transfer and quadrupole settings are set to Funnel RF 350 Vpp; Multipole RF 400 Vpp as transfer settings and lon energy of $5 \mathrm{eV}$ as well as a low mass cut of $300 \mathrm{~m} / \mathrm{z}$ as Quadrupole settings. Collision cell is set to $5.0 \mathrm{eV}$ and pre pulse storage 
time is set to $5 \mu \mathrm{s}$. Spectra acquisition rate is set to $2 \mathrm{~Hz}$. Calibration is done automatically before every UPLC-hrMS run by injection of a sodium formate calibrant solution and calibration on the sodium formate clusters forming in the ESI source. All MS analyses are acquired in the presence of the lock masses $\mathrm{C}_{12} \mathrm{H}_{19} \mathrm{~F}_{12} \mathrm{~N}_{3} \mathrm{O}_{6} \mathrm{P}_{3} ; \mathrm{C}_{18} \mathrm{H}_{19} \mathrm{O}_{6} \mathrm{~N}_{3} \mathrm{P}_{3} \mathrm{~F}_{2}$ and $\mathrm{C}_{24} \mathrm{H}_{19} \mathrm{~F}_{36} \mathrm{~N}_{3} \mathrm{O}_{6} \mathrm{P}_{3}$, which generate the $[\mathrm{M}+\mathrm{H}]^{+}$ions of 622.028960 ; 922.009798 and 1221.990638 .

\section{Isolation, purification and characterization of 3,5 dibromo p-anisic acid}

\subsection{Isolation of 3,5 dibromo p-anisic acid}

The crude fermenter broth consisting of cells and XAD-16 resin were harvested by centrifugation on a Beckmann Avanti J-26 XP with the JLA 8.1 rotor at 6000 rcf. Combined resin and cells were extracted successively with $2 \times 250 \mathrm{ml}$ of technical grade methanol (Fluka) and $2 \times 250 \mathrm{ml}$ of technical grade acetone (Fluka). The extracts were combined, filtered through a $2 \mu \mathrm{m}$ pore diameter paper filter and all solvent was evaporated on a rotary evaporator. The crude extract was partitioned between hexane and methanol in a separatory funnel, the methanol phase was dried on a rotary evaporator and the residue is partitioned between ethyl acetate and water. 3,5 dibromo p-anisic acid remained almost exclusively in the ethyl acetate layer. The ethyl acetate layer was dried again and taken in a minimum volume of methanol for flash chromatography. Flash chromatography was performed on a Biotage Isolera one system on a $25 \mathrm{~g}$ cartridge filled with C-18 coated silica gel with a column volume of $45 \mathrm{ml}$. Separation was performed with Water as A and Acetonitrile as B and a flow rate of $50 \mathrm{ml} / \mathrm{min}$. Chromatographic separation contains $2 \mathrm{CV}$ of $95 \% \mathrm{~A}$ followed by a gradient to $100 \% \mathrm{~B}$ during $6 \mathrm{CV}$. The chromatographic run is separated into fractions of $8 \mathrm{ml}$ and those containing 3,5 dibromo p-anisic acid were combined for further purification. Further purification was done using a Dionex Ultimate 3000 SDLC low pressure gradient system on a Phenomenex Luna C18-2 250x10mm 5 $\mu$ m column with the eluents $\mathrm{H} 2 \mathrm{O}+0.1 \% \mathrm{FA}$ as $\mathrm{A}$ and $\mathrm{ACN}+0.1 \% \mathrm{FA}$ as $\mathrm{B}$, a flow rate of $5 \mathrm{ml} / \mathrm{min}$ and a column thermostated at $30^{\circ} \mathrm{C}$. B content is kept at $10 \%$ for 2 minutes followed by a linear gradient to $45 \%$ B during 36 minutes. B content was then ramped to $95 \%$ in 2 minutes and kept at $95 \%$ for 3 minutes to flush the column. B content was ramped back to initial conditions during $30 \mathrm{~s}$ and the column is reequilibrated for 1.5 minutes. The compound could be detected with a UV detector at $220 \mathrm{~nm}$ wavelength. After drying, 3,5 dibromo p-anisic acid was obtained as a white amorphous solid. 


\subsection{NMR Data of 3,5 dibromo p-anisic acid}

1D and 2D NMR data used for structure elucidation of 3,5 dibromo p-anisic acid was acquired in Methanol- $d_{4}$ and DMSO- $\mathrm{d}_{6}$ on a Bruker Avance III HD 500 UltraShield spectrometer with a $5 \mathrm{~mm}$ TXI cryoprobe $\left({ }^{1} \mathrm{H}\right.$ at $500 \mathrm{MHz},{ }^{13} \mathrm{C}$ at $\left.125 \mathrm{MHz}\right) \mathrm{NMR}$ spectrometer. To elucidate the planar structure of the molecules ${ }^{1} \mathrm{H},{ }^{13} \mathrm{C}$ as well as $\mathrm{H}-\mathrm{H}$ DQFCOSY, HSQC and HMBC data are acquired. DQFCOSY, HSQC, HMBC, and ROESY experiments were recorded using standard pulse programs. The NMR signals were grouped in the tables below and correspond to the numbering in the scheme above.

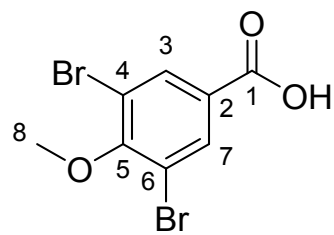

Figure S 5. Structure formula of 3,5 dibromo p-anisic acid including carbon numbering used in NMR analysis

Table 4. Tabulated $1 D$ and 2D NMR signal for 3,5 dibromo $p$-anisic acid in DMSO-d 6

\begin{tabular}{|c|ccccc|}
\hline $\begin{array}{c}\text { Carbon } \\
\text { number }\end{array}$ & ${ }^{13}$ C shift & ${ }^{1} \mathrm{H}$ shift & $\begin{array}{c}\text { J, multiplicity, } \\
\text { number of protons }\end{array}$ & $\begin{array}{c}\mathrm{H}-\mathrm{H} \text { COSY } \\
\text { correlations }\end{array}$ & $\begin{array}{c}\mathrm{HMBC} \\
\text { correlations }\end{array}$ \\
\hline 1 & 171.3 & - & & - & - \\
2 & 137.9 & - & & - & - \\
3,7 & 134.9 & 8.11 & $\mathrm{~S}, 2 \mathrm{H}$ & - & $118.1,134.9,137.9,156.8,171.3$ \\
4,6 & 118.1 & - & & - & - \\
5 & 156.8 & - & & - & - \\
8 & 61.0 & 3.87 & $\mathrm{~S}, 3 \mathrm{H}$ & - & 156.8 \\
\hline
\end{tabular}

Table 5. Tabulated 1D and 2D NMR signal for 3,5 dibromo p-anisic acid in $\mathrm{MeOH}-d_{4}$

\begin{tabular}{|c|ccccc|}
\hline $\begin{array}{c}\text { Carbon } \\
\text { number }\end{array}$ & ${ }^{13} \mathrm{C}$ & ${ }^{1} \mathrm{H}$ shift & $\begin{array}{c}\text { J, multiplicity, } \\
\text { number of protons }\end{array}$ & $\begin{array}{c}\mathrm{H}-\mathrm{H} \text { COSY } \\
\text { correlations }\end{array}$ & $\begin{array}{c}\mathrm{HMBC} \\
\text { correlations }\end{array}$ \\
\hline 1 & 164.4 & - & & - & - \\
2 & 140.1 & - & & - & - \\
3,7 & 132.6 & 7.95 & $\mathrm{~s}, 2 \mathrm{H}$ & - & $116.0,132.6,140.1,152.9,164.4$ \\
4,6 & 116.0 & - & & - & - \\
5 & 152.9 & - & & - & - \\
8 & 60.2 & 3.78 & $\mathrm{~s}, 3 \mathrm{H}$ & - & 152.9 \\
\hline
\end{tabular}




\section{Genetic characterization of the Baa gene cluster}

\subsection{Antibiotics resistance tests for strain 10988}

In order to attempt the creation of mutant clones of 10988 to prove the origin of 3,5 dibromo $p$-anisic acid experimentally we explored the possibility to use resistance markers in 10988. Although there have been some reports on mutagenesis of planctomycetes, only a couple of planctomycetes have been genetically manipulated successfully so far. $[4,6]$

Table 6. Antibiotics sensitivity tests performed on 10988

\begin{tabular}{|l|c|}
\hline Antibiotic & highest concentration tested [ng/ml] \\
\hline oxytetracycline & 50 \\
\hline kanamycin & 200 \\
\hline ampicillin & 200 \\
\hline streptomycin & 25 \\
\hline chloramphenicol & 50 \\
\hline apramycin & 50 \\
\hline hygromycin E & \\
\hline
\end{tabular}

Unfortunately, the strain showed high resistance to all tested antibiotics. We were therefore unable to perform genetic manipulations with the strain as we could not obtain a viable resistance marker. We were thus also unable to inactivate the 3,5 dibromo p-anisic acid via single crossover homologous recombination.

\subsection{Genome sequencing and gene cluster annotation and Accession number}

Genomic DNA of strain 10988 was isolated using phenol/chloroform based Isolation of bacterial genomic DNA. SMRTbell ${ }^{\mathrm{TM}}$ template library was prepared according to the instructions from PacificBiosciences, Menlo Park, CA, USA, following the Procedure \& Checklist Greater than $10 \mathrm{~kb}$ Template Preparation and Sequencing. Briefly, for preparation of $10 \mathrm{~kb}$ libraries $\sim 10 \mu \mathrm{g}$ genomic DNA was endrepaired and ligated overnight to hairpin adapters applying components from the DNA/Polymerase Binding Kit P4 from Pacific Biosciences, Menlo Park, CA, USA. Reactions were carried out according to the 
manufacturer's instructions. SMRTbell ${ }^{\mathrm{TM}}$ template was Exonuclease treated for removal of incompletely formed reaction products. Conditions for annealing of sequencing primers and binding of polymerase to purified SMRTbell ${ }^{\mathrm{TM}}$ template were assessed with the Calculator in RS Remote, PacificBiosciences, Menlo Park, CA, USA. SMRT sequencing was carried out on the PacBio RS (PacificBiosciences, Menlo Park, CA, USA) taking one 240-minutes movie. PacBio sequencing resulted in 55,213 reads with a mean read length of 12,221 bp. Genome assembly was performed applying the RS_HGAP_Assembly.3 protocol included in SMRT Portal version 2.3.0 applying default parameters and resulted in a one contig sequence covered 85x. The genome of Planctomycetales strain 10988 consists of a single circular bacterial chromosome with $6,649,439$ base pairs. This gene cluster prediction does not include the genomic locus responsible for the production of 3,5-dibromo-p-anisic acid as this polybrominated compound was not biosynthesized by a megasynthase detectable by antiSMASH through hidden markov models. [1] The genome of planctomycetal strain 10988 was deposited at GenBank and can be retrieved under GenBank Accession number CP043547.

\subsection{Phyre 2 results for modelling the planctomycetal enzymes BaaA and BaaB}

When modelling the BaaA protein on the protein fold recognition server Phyre 2 two hit fold structures are retrieved that show a $100 \%$ confidence model based on a PDB structure. The first of these hits was a chorismate lyase from Archaeoglobus fulgidus (PDB 2NWI) (Bonanno et al. unpublished results), while the second hit is an E. coli chorismate lyase (PDB 1TT8).[5]

Modelling of the BaaB protein on the protein fold recognition server Phyre 2 we could retrieve 60 homology models to PDB crystal structures that show $100 \%$ confidence. All of these proteins folds belong to the class of FAD dependent halogenases and oxygenases. The closest relative of BaaB in the PDB is the halogenase $\mathrm{CmIS}$ from the chloramphenicol biosynthesis in S. venezuelae (PDB 3|3L) and the second closest relative is the pyoluteorin chlorinating enzyme PItA from $P$. aeruginosa (PDB 5DBJ). [2, 3] Based on these two enzymes $\mathrm{BaaA}$ and $\mathrm{BaaB}$ being clustered together it was very likely that they are responsible for formation of 3,5-dibromo-p-anisic acid.

\subsection{Comparison of the BaaB brominase to the Bmp5 enzymes}

To assess the degree of structural novelty of the BaaB brominase when compared to their bromophenol producing congeners from Pseudoaltheromonas strains called Bmp5 proteins we compared 
the brominases on a sequence level. While the two brominating enzymes from $P$. luteoviolacea and $P$. phenolica that have been shown to polybrominate phenols are strikingly similar with a homology of $96 \%$ the homology of the planctomycetal BaaB to either of the Bmp5 proteins is only about $44 \%$.

Table S 1. Pairwise homology of BaaB and the Bmp5 enzymes

\begin{tabular}{|c|c|c|c|}
\hline & $\begin{array}{c}\text { BaaB } \\
\text { Planctomycetal species } 10988\end{array}$ & $\begin{array}{c}\text { Bmp5 } \\
\text { P. luteoviolacea } 2 \text { ta } 16\end{array}$ & $\begin{array}{c}\text { Bmp5 } \\
\text { P. phenolica } \mathrm{O}-\mathrm{BC} 30\end{array}$ \\
\hline \multirow{3}{*}{$\begin{array}{c}\text { BaaB } \\
\text { Planctomycetal species } 10988 \\
\text { Bmp5 } \\
\text { P. luteoviolacea } 2 \text { ta16 } \\
\text { Bmp5 } \\
\text { P. phenolica O-BC30 }\end{array}$} & & $43.73 \%$ & $43.96 \%$ \\
\hline & $43.73 \%$ & & $96.98 \%$ \\
\hline & $43.96 \%$ & $96.98 \%$ & \\
\hline
\end{tabular}

\subsection{Candidate enzymes for the 0-methyl transferase BaaC}

Unfortunately, it became clear that the biosynthetic gene cluster responsible for the production of 3,5 dibromo $p$-anisic acid does not contain a SAM dependent O-methyl transferase domain protein. When analyzing the Planctomycetes sp. 10988 species by blast using two phenolic O-methyl transferases as probe sequences, we retrieve 8 target sequences that show high similarity to both query sequences. The two query sequences were the O-methyl transferase involved in retrieving these target sequences are the O-methyl transferase StiK responsible for SAM-dependent methyl transfer in Stigmatellin biosynthesis in S. aurantiaca (NCBI protein acc. Nr. CAD19094.1) and the E. coli K-12 protein responsible for O-methyl transfer in Ubiquinone biosynthesis UbiG (NCBI protein acc. Nr. BAA16049.1) that both catalyze similar reactions. Locus tags of these identified $\mathrm{BaaC}$ candidates are Methyltransferase 530, Methyltransferase 21270, Methyltransferase 22400, Methyltransferase 23570, Methyltransferase 27160, Methyltransferase 28040, Methyltransferase 32880 and Methyltransferase 36580. As we did not have any means to perform genetic manipulation on 10988 we had no means of identifying the methyl transferase performing this methylation reaction among these 8 candidates. 


\section{Bioactivity assays}

\subsection{Origin of the assayed compounds}

3,5 dibromo p-hydroxybenzoeic acid (2) and Methyl 3,5 dibromo p-hydroxybezoeic acid (3) were obtained from the commercial chemical supplier Alfa Aesar (Kandel, Germany). Additional 3,5 dibromo panisic acid (1) was obtained from Fluorochem Ltd. (Derbyshire, UK). Identity of $\mathbf{1}$ obtained from a commercial source to its natural product counterpart was assayed by NMR analysis, UHPLC retention time and the LC-MS² spectrum.

\subsection{Antimicrobial Assay}

All microorganisms were handled according to standard procedures and were obtained from the German Collection of Microorganisms and Cell Cultures (Deutsche Sammlung für Mikroorganismen und Zellkulturen, DSMZ) or were part of our internal strain collection. For micro dilution assays, overnight cultures of Gram-positive bacteria in Müller-Hinton broth $(0.2 \%(w / v)$ beef infusion, $0.15 \%(w / v)$ corn starch, $1.75 \%(\mathrm{w} / \mathrm{v})$ casein peptone; $\mathrm{pH} 7.4)$ were diluted in the growth medium to achieve a final inoculum of ca. $10^{6} \mathrm{cfu} \mathrm{ml}^{-1}$. Serial dilutions of the brominated benzoeic acid derivatives were prepared from freshly prepared Methanol stocks in sterile 96-well plates. The cell suspension was added and microorganisms were grown on a microplate shaker (750 rpm, $37^{\circ} \mathrm{C}$ and $\left.16 \mathrm{~h}\right)$. Growth inhibition was assessed by visual inspection and given MIC (minimum inhibitory concentration) values are the lowest concentration of antibiotic at which no visible growth was observed.

\subsection{Cytotoxic Activity}

Cell lines were obtained from the German Collection of Microorganisms and Cell Cultures (Deutsche Sammlung für Mikroorganismen und Zellkulturen, DSMZ) or were part of our internal collection and were cultured under conditions recommended by the depositor. Cells were seeded at $6 \times 10^{3}$ cells per well of 96-well plates in $180 \mu \mathrm{l}$ complete medium and treated with the brominated benzoeic acid derivatives in serial dilution after $2 \mathrm{~h}$ of equilibration. Each compound was tested in duplicate as well as the internal solvent control. After $5 \mathrm{~d}$ incubation, $20 \mu \mathrm{l}$ of $5 \mathrm{mg} \mathrm{ml}^{-1} \mathrm{MTT}$ (thiazolyl blue tetrazolium bromide) in PBS was added per well and it was further incubated for $2 \mathrm{~h}$ at $37^{\circ} \mathrm{C}$. The medium was discarded and cells were 
washed with $100 \mu \mathrm{l}$ PBS before adding $100 \mu \mathrm{l}$ 2-propanol/10 N HCl (250:1) in order to dissolve formazan granules. The absorbance at $570 \mathrm{~nm}$ was measured using a microplate reader (Tecan Infinite M200Pro), and cell viability was expressed as percentage relative to the respective methanol control. IC $C_{50}$ values were determined by sigmoidal curve fitting.

\subsection{Herbicidal activity assays}

A. stolonifera penncross seeds were grown in plant medium consisting of Serva 47516.03 Murashige \& Skoog plant salts (2.2 g/L) and Gamborg's B-5 Basal Medium with Minimal Organics (1.6 g/L) in deionized water. The essay was performed in sterile 96 well flat bottom well plates containing ca. 10 seeds, $195 \mu \mathrm{L}$ of plant medium and $5 \mu \mathrm{L}$ of the assayed compound per well. Positive controls were performed using solely plant medium as well as plant medium with methanol. The prepared 96 well plates were incubated for 6 days in a Grow light Garden illumination chamber to germinate the $A$. stolonifera seeds. Inhibition was determined by visual inspection of the respective wells. Herbicidal activity was detected by a lack of germination in the respective wells, wells containing more than 5 germinated plant seeds count as not inhibited.

Table S 2. 96 well plate layout for the herbicidal assay, Cmp.1 is 3,5 dibromo p-hydroxybenzoeic acid methyl ester, Cmp. 2 is 3,5 dibromo p-anisic acid and Cmp. 3 is 3,5 dibromo p-hydroxybenzoeic acid

\begin{tabular}{|c|c|c|c|c|c|c|c|c|c|c|}
\hline & 1 & 2 & 3 & 4 & 5 & 6 & 7 & 8 & 9 & 10 \\
\hline A & $\begin{array}{l}\text { MeOH } \\
\text { blank }\end{array}$ & $\begin{array}{c}0.25 \\
\mathrm{mg} / \mathrm{ml} \\
\text { Cmp. } 1\end{array}$ & $\begin{array}{c}0.25 \\
\mathrm{mg} / \mathrm{ml} \\
\text { Cmp. } 2\end{array}$ & $\begin{array}{c}0.125 \\
\mathrm{mg} / \mathrm{ml} \\
\text { Cmp. } 1\end{array}$ & $\begin{array}{c}0.125 \\
\mathrm{mg} / \mathrm{ml} \\
\text { Cmp. } 2\end{array}$ & $\begin{array}{l}0.0625 \\
\mathrm{mg} / \mathrm{ml} \\
\text { Cmp. } 1\end{array}$ & $\begin{array}{l}0.0625 \\
\mathrm{mg} / \mathrm{ml} \\
\mathrm{Cmp} .2\end{array}$ & $\begin{array}{c}0.25 \\
\mathrm{mg} / \mathrm{ml} \\
\text { Cmp. } 3\end{array}$ & $\begin{array}{c}0.125 \\
\mathrm{mg} / \mathrm{ml} \\
\text { Cmp. } 3\end{array}$ & $\begin{array}{l}0.0625 \\
\mathrm{mg} / \mathrm{ml} \\
\mathrm{Cmp} .3\end{array}$ \\
\hline B & $\begin{array}{c}\text { MeOH } \\
\text { blank }\end{array}$ & $1: 2$ & $1: 2$ & $1: 2$ & $1: 2$ & $1: 2$ & $1: 2$ & $1: 2$ & $1: 2$ & $1: 2$ \\
\hline C & $\begin{array}{l}\mathrm{MeOH} \\
\text { blank }\end{array}$ & $1: 4$ & $1: 4$ & $1: 4$ & $1: 4$ & $1: 4$ & $1: 4$ & $1: 4$ & $1: 4$ & $1: 4$ \\
\hline D & $\begin{array}{c}\text { MeOH } \\
\text { blank }\end{array}$ & $1: 8$ & $1: 8$ & $1: 8$ & $1: 8$ & $1: 8$ & $1: 8$ & $1: 8$ & $1: 8$ & $1: 8$ \\
\hline$E$ & $\begin{array}{c}\text { plant } \\
\text { medium } \\
\text { blank }\end{array}$ & $1: 16$ & $1: 16$ & $1: 16$ & $1: 16$ & $1: 16$ & $1: 16$ & $1: 16$ & $1: 16$ & $1: 16$ \\
\hline $\mathrm{F}$ & $\begin{array}{c}\text { plant } \\
\text { medium } \\
\text { blank }\end{array}$ & $1: 32$ & 1:32 & $1: 32$ & 1:32 & 1:32 & $1: 32$ & $1: 32$ & $1: 32$ & 1:32 \\
\hline G & $\begin{array}{c}\text { plant } \\
\text { medium } \\
\text { blank }\end{array}$ & 1:64 & 1:64 & 1:64 & 1:64 & 1:64 & $1: 64$ & 1:64 & 1:64 & $1: 64$ \\
\hline $\mathrm{H}$ & $\begin{array}{c}\text { plant } \\
\text { medium } \\
\text { blank }\end{array}$ & $1: 128$ & $1: 128$ & $1: 128$ & $1: 128$ & $1: 128$ & $1: 128$ & 1:128 & $1: 128$ & $1: 128$ \\
\hline
\end{tabular}


Table S 3. Number of germinated seeds per well in the 96 well plate herbicidal assay

\begin{tabular}{c|ccccccccccc} 
& 1 & 2 & 3 & 4 & 5 & 6 & 7 & 8 & 9 & 10 \\
\hline $\mathrm{A}$ & $>5$ & & 0 & 0 & 0 & 0 & 0 & 0 & 0 & 1 & 2 \\
$\mathrm{~B}$ & $>5$ & & 0 & 1 & 0 & 3 & $>5$ & $>5$ & 0 & 4 & $>5$ \\
$\mathrm{C}$ & $>5$ & & 0 & 4 & 1 & $>5$ & $>5$ & $>5$ & $>5$ & $>5$ & $>5$ \\
$\mathrm{D}$ & $>5$ & & 3 & $>5$ & $>5$ & $>5$ & $>5$ & $>5$ & $>5$ & $>5$ & $>5$ \\
$\mathrm{E}$ & $>5$ & $>5$ & $>5$ & $>5$ & $>5$ & $>5$ & $>5$ & $>5$ & $>5$ & $>5$ \\
$\mathrm{~F}$ & $>5$ & $>5$ & $>5$ & $>5$ & $>5$ & $>5$ & $>5$ & $>5$ & $>5$ & $>5$ \\
$\mathrm{G}$ & $>5$ & $>5$ & $>5$ & $>5$ & $>5$ & $>5$ & $>5$ & $>5$ & $>5$ & $>5$ \\
$\mathrm{H}$ & $>5$ & $>5$ & $>5$ & $>5$ & $>5$ & $>5$ & $>5$ & $>5$ & $>5$ & $>5$
\end{tabular}

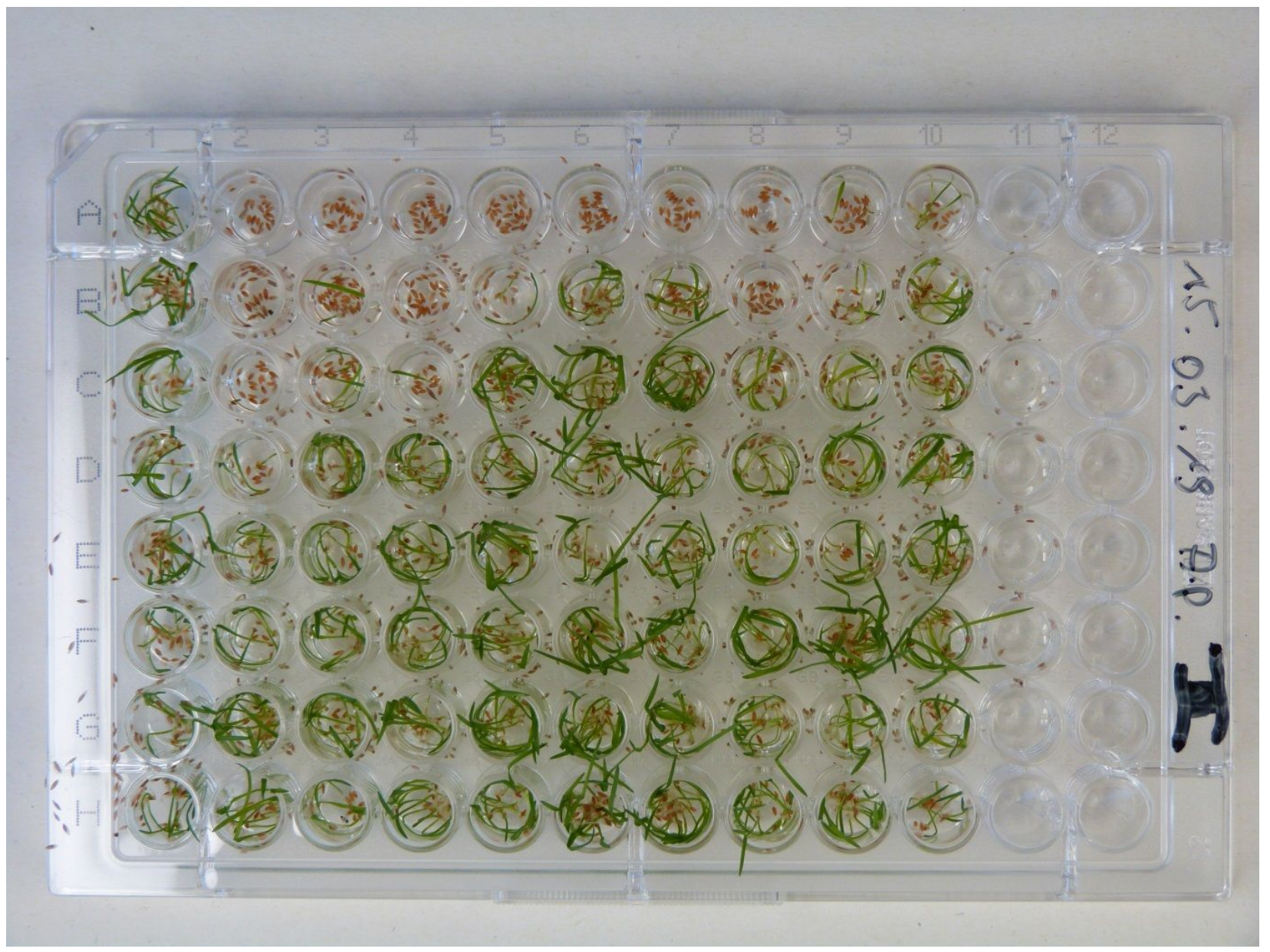

Figure S 6. Agrostis stolonifera penncross based Herbicide assay 


\section{NMR spectra of natural 3,5 dibromo p-anisic acid}

This section contains the NMR spectra of the 3,5 dibromo p-anisic acid isolated from the planctomyces strain 10988 in $\mathrm{MeOH}-d 4$. 


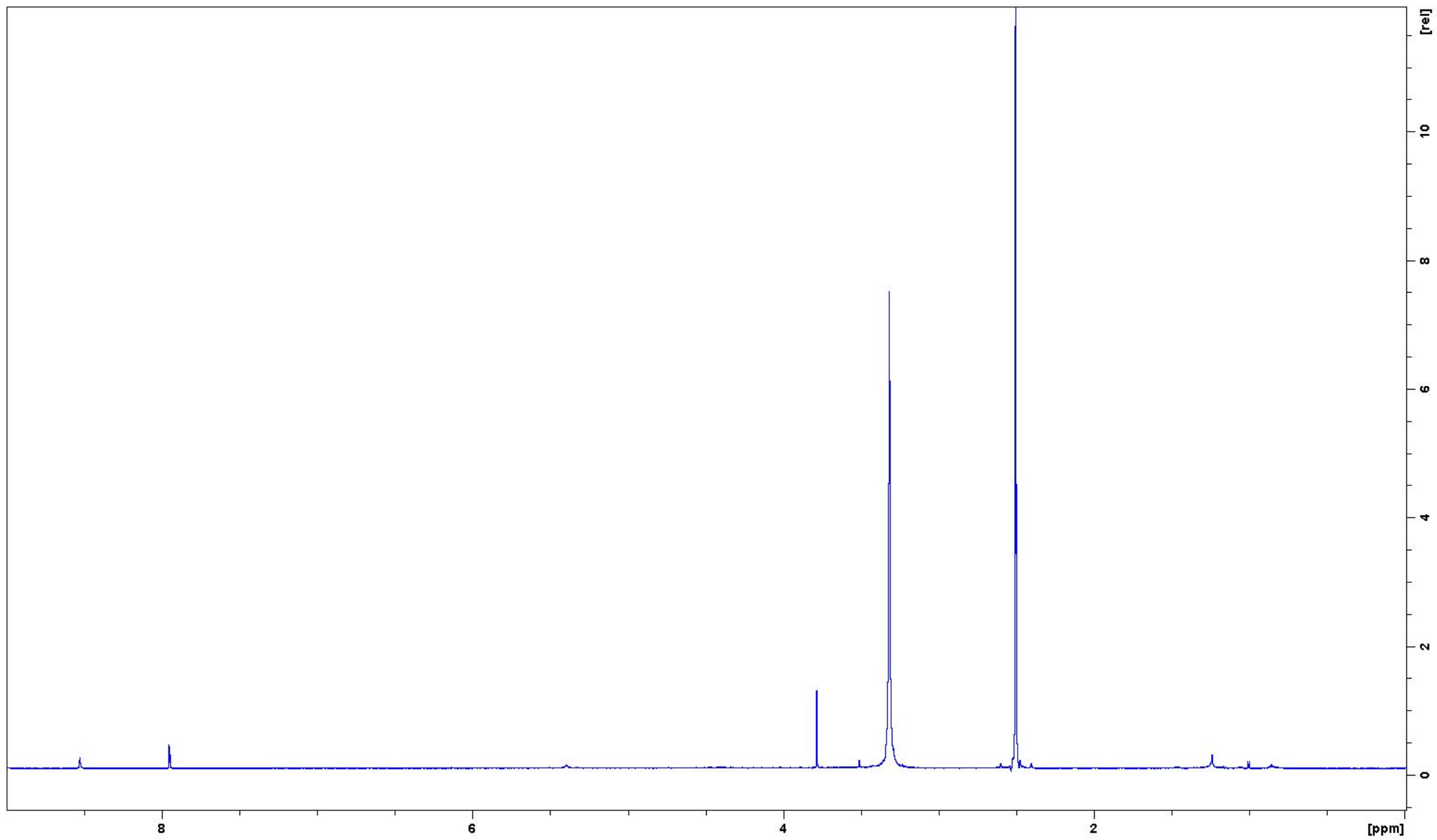

Figure S 7. ${ }^{1} \mathrm{H} N \mathrm{NR}$ spectrum of isolated 3,5 dibromo p-anisic acid in $\mathrm{MeOH}-\mathrm{d} 4$ 


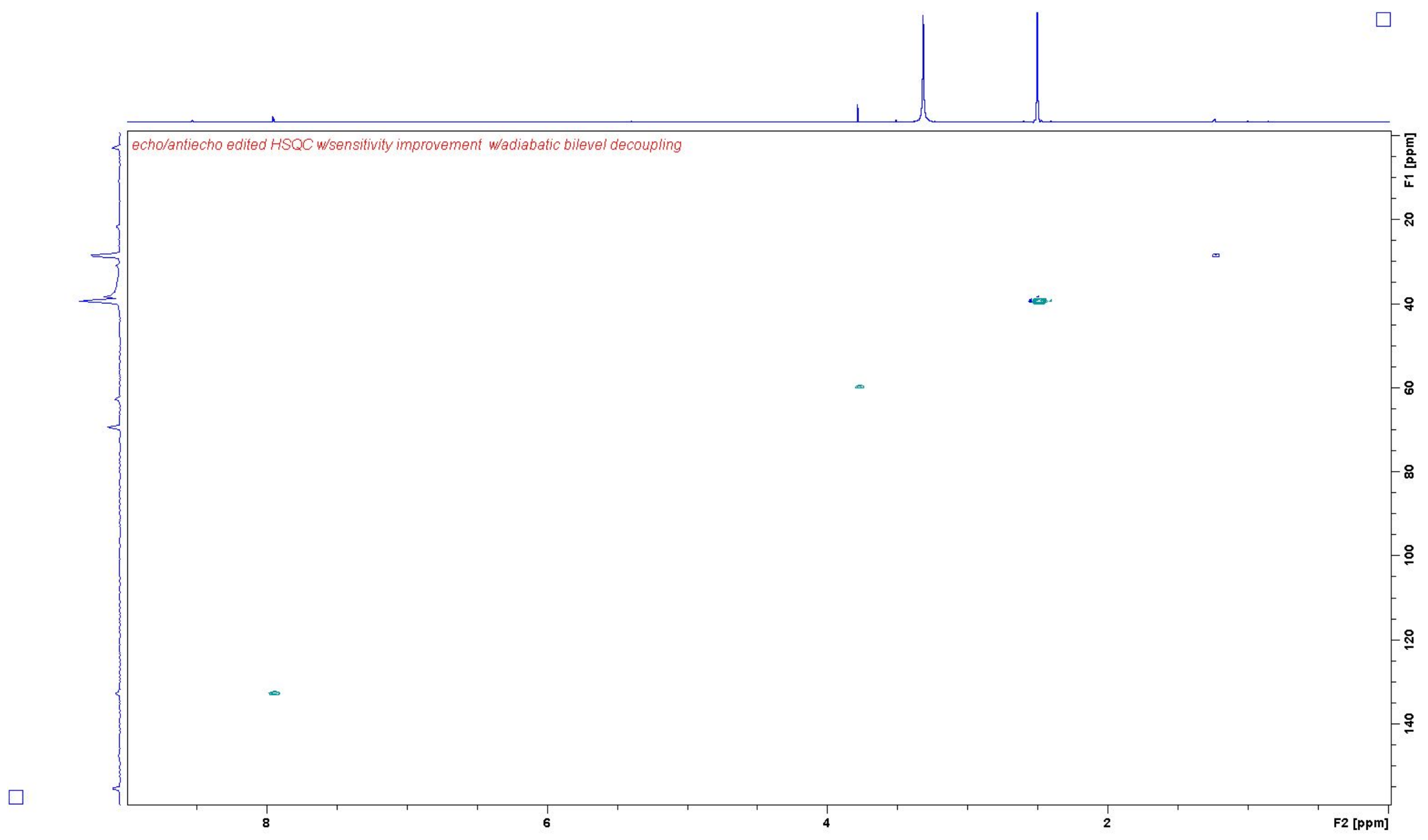

Figure S 8. HSQC spectrum of isolated 3,5 dibromo p-anisic acid in $\mathrm{MeOH}-\mathrm{d} 4$ 


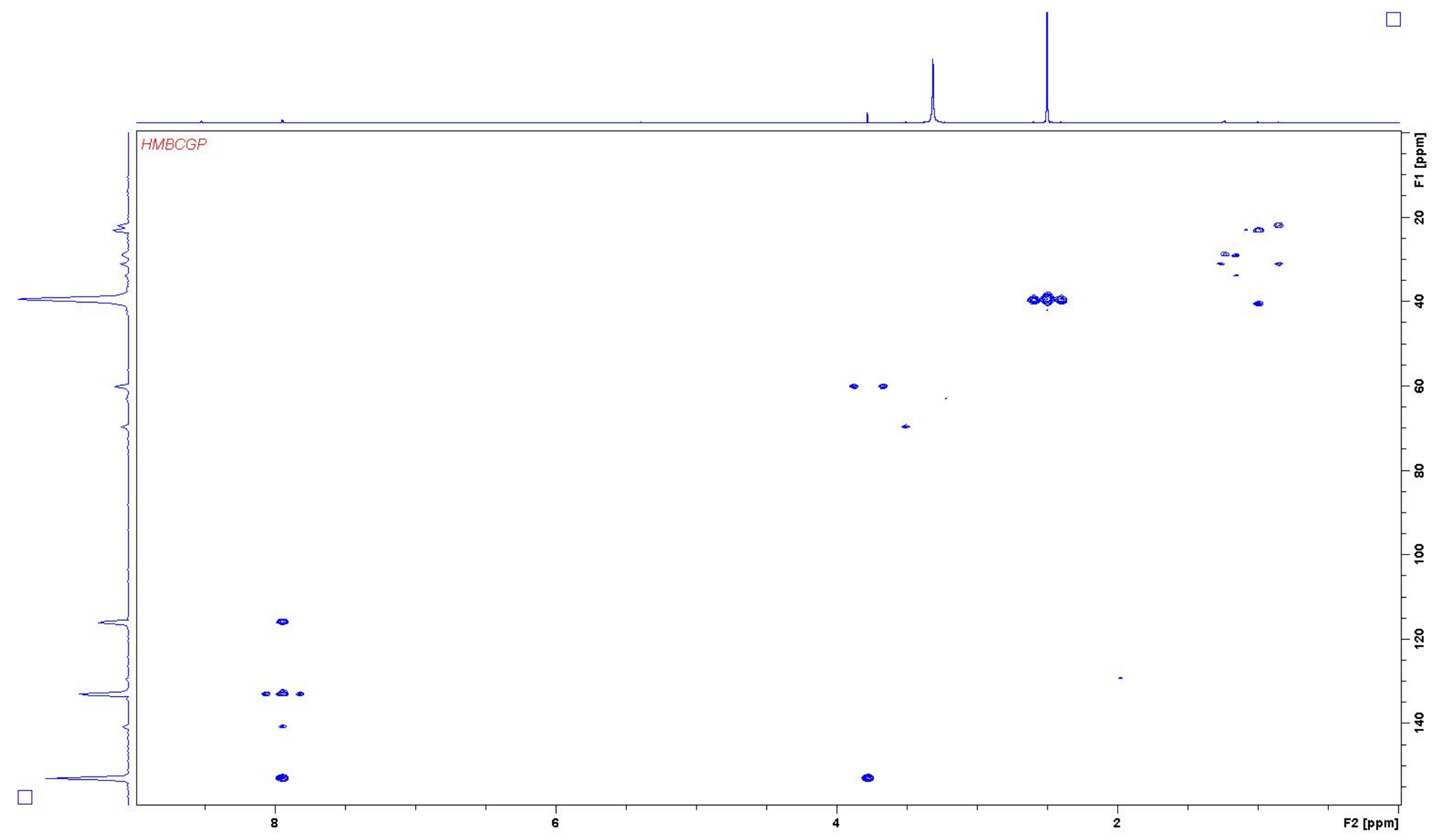

Figure S 9. HMBC spectrum of isolated 3,5 dibromo p-anisic acid in $\mathrm{MeOH}$-d4 


\section{References}

[1] Blin, K., Shaw, S., Steinke, K., Villebro, R., Ziemert, N., Lee, S. Y., Medema, M. H., and Weber, T. 2019. antiSMASH 5.0: updates to the secondary metabolite genome mining pipeline. Nucleic Acids Res., 47, W81-W87.

[2] Pang, A. H., Garneau-Tsodikova, S., and Tsodikov, O. V. 2015. Crystal structure of halogenase PltA from the pyoluteorin biosynthetic pathway. J. Struct. Biol. 192, 3, 349-357.

[3] Podzelinska, K., Latimer, R., Bhattacharya, A., Vining, L. C., Zechel, D. L., and Jia, Z. 2010. Chloramphenicol biosynthesis: the structure of $\mathrm{CmIS}$, a flavin-dependent halogenase showing a covalent flavin-aspartate bond. J. Mol. Biol. 397, 1, 316-331.

[4] Rivas-Marín, E., Canosa, I., Santero, E., and Devos, D. P. 2016. Development of Genetic Tools for the Manipulation of the Planctomycetes. Front. Microbiol. 7, 914.

[5] Smith, N., Roitberg, A. E., Rivera, E., Howard, A., Holden, M. J., Mayhew, M., Kaistha, S., and Gallagher, D. T. 2006. Structural analysis of ligand binding and catalysis in chorismate lyase. Arch. Biochem. Biophys. 445, 1, 72-80.

[6] Wiegand, S., Jogler, M., and Jogler, C. 2018. On the maverick Planctomycetes. FEMS Microbiol. Rev. 42, 6, 739-760. 